\title{
A Personal Narrative of Resilience - Working in a Top Management Office at a University of Technology
}

\author{
Prof. Kholeka Constance Moloi \\ Vaal University of Technology, Faculty of Human Sciences, \\ Vanderbijlpark, 1900, South Africa \\ Email:conniem@vut.ac.za

\section{Ms Gapenyane Mercia Secwalo} \\ Vanderbijlpark, 1900, South Africa \\ Email: gapenyanes@vut.ac.za
}

\section{Doi:10.5901/mjss.2014.v5n3p422}

\section{Abstract}

This article discusses the experiences of one of the authors working in a top management office in one University of Technology. Despite misgivings which have sometimes culminated in assertions that overall, resilience as a construct is of dubious scientific value, the authors deem it pertinent as a theoretical perspective for this paper. The authors are also aware that critiques have generally focused on ambiguities in definitions and the central terminology of resilience. Given the stressful nature of the work situation of one of the authors, we are inclined to the definition of resilience as the maintenance of positive adaptation by individuals despite experiences of significant adversity or stressful work situations. We also are of the opinion that resilience is not static. We agree with Luther, Cicchetti and Becker (2007:543) that work on resilience possesses substantial potential for augmenting the understanding of processes affecting at-risk individuals, as is the case with one of the authors of this article.

Keywords: Overload, stress, resilience,

\section{Introduction}

The rationale for this theoretical exploration proceeds from the number of challenges experienced by one of the authors as an executive secretary in one office of top management at a University of Technology in South Africa. She was appointed to the office in April, 2009. At the time, there were two other executive secretaries in the office reporting to one line manager until the end of March 2011. One of the two secretaries moved to a higher position as a lecturer and since then it has been difficult for the position to be filled. From April to September 2011 the position was vacant, and in the meantime, secretaries from different offices were requested to assist as needed, until someone was appointed on a contract from one of the employment agencies (Kelly) from October 2011. This came as an afterthought, after two candidates in succession, who had been interviewed when the position was advertised externally and had accepted the offer, had declined at the eleventh hour. One of the candidates, after requesting permission to serve notice of two months so that she could sell her house and find a school for her children, decided to remain with her previous employer. It became apparent later that she had used the offer for this position to negotiate a counter-offer at her previous company.

The new employee stayed with the department for just over a year and left in March 2013, mainly because the position had been advertised externally and she had not been shortlisted as she did not meet the minimum requirements for the position. She then got another position within the institution. Before she was appointed, someone who had been given a contract to assist in this top management office left within a week, stating that this position was not meant for her. She had thought that the position was that of a manager. The position was again advertised, internally this time, but it was frozen due to unforeseen circumstances and has since been vacant (until November 2013). I have since been manning the office on my own and this has made it difficult for me to get through all the tasks as this is a top management office which requires concentration, taking on extra work, paying attention to detail and, in general, being on top of one's game. I have had to work for very long hours, sometimes leaving the office at 10 in the evening.

The duties I have been assigned include, among others, taking minutes for different committees and for different 
stakeholders with whom the Vice Chancellors hold meetings, managing the diaries of my line manager (manually and electronically), office filing, reading and responding to e-mails, making travel arrangements, answering and screening calls and routing them to the relevant people, ordering office furniture and stationery, arranging meetings and preparing venues for meetings, typing speeches and reports, preparing the office budget and being responsible for it, making out requisitions, paying suppliers, training new staff, assisting others as needs arise and liaising with external stakeholders. The combination of all these tasks and responsibilities sits heavily on my shoulders.

\section{Problem Statement}

A comparison with regard to the human capacity of this specific office has been done in relation to the same office of the other five universities of technology. The human capacity in these five other universities is a follows:

(i) Central University of Technology - the office consists of one office manager reporting to the line manager, and an office assistant, who reports to the office manager.

(ii) Mangosuthu University of Technology - one acting executive secretary reports to two managers. The executive director was appointed after the secretary.

(iii) Durban University of Technology - the office consist of one executive secretary reporting to one line manager.

(iv) Tshwane University of Technology - One executive secretary reporting to one line manager.

(v) Cape Peninsula University of Technology - the office consists of two executive secretaries and an office assistant, because there are two campuses - the Bellville Campus and the Cape Town Campus - and they share the work amongst the three of them with the assistant running some minor errands for them.

The difference is that one of the authors is the only executive secretary in the office as compared with the situation in the other five universities of technology, reporting to three line managers, namely the Vice-Chancellor, the Executive Director and the Director. She has to report to all three on her own. We argue that lack of capacity in the top management office could be one of the reasons for employee turnover. This is important because it affects the turnaround and delivery time of the duties within the office, deprives the other employees in this office of family time as they have to work overtime and take work home so as to not fall behind schedule. Since the duties were to be shared between two people, it is a waste of time training contract employees who will end up leaving as soon as they get permanent positions elsewhere in the institution. This problem is of current interest in the office as the problem escalates. The Executive Director and the Director were appointed without any support staff, which means that one person (one of the authors) is expected to also assist the two with administrative support.

In attempting to investigate the resilience of staff members in the top management office, the questions posed in this paper for the purpose of this research are:

- What is the meaning of resilience?

- How can we improve employee resilience in the workplace?

- Why is resilience important in the workplace?

\section{Objectives of the Study}

The objectives of this study are to:

- Explain the meaning of resilience.

- Investigate how to improve resilience in the workplace.

Explore the importance of resilience in the workplace.

\section{Explanation of the Construct of Resilience}

Luthar, Cicchetti and Becker (2007:543) have pointed out that there are discrepancies in conceptualisations of resilience as a personal trait versus a dynamic process. These researchers use the term interchangeably to refer to each of these terms (personal trait versus a dynamic process). They point out that this confusion regarding the issue of trait versus process derives, in part, from the influential literature on ego-resiliency, a construct that was developed by Jeanne and Block (1980) and which refers to a personal characteristic of the individual. According to Luther et al., ego resiliency encompasses a set of traits reflecting general resourcefulness and sturdiness of character and flexibility of functioning in response to varying environmental circumstances (p. 546). It is used to refer to the two coexisting conditions of resilience - the presence of threat to a given child's well-being and evidence of positive adaptation in this child, despite the 
adversity encountered. They caution that in future research efforts, it is imperative that investigators exercise caution in their use of terminology, with clear indication when their work is focused on a process and not a personality trait. Given the work situation of one of the authors, we believe that the resilience theory explains how she has managed to be in this top management office despite the stressful situation in which she works.

Resilience refers to a dynamic process encompassing positive adaptation within the context of significant adversity. Implicit within this notion are two critical conditions: (1) exposure to significant threat or severe adversity; and (2) the achievement of positive adaptation despite major assaults on the developmental process (Luthar et al. 2007:543). According to Du Plessis \& Van Breda (2001:2), resilience theory, although it has been evolving over the past 70-80 years, has enjoyed a renaissance in the past two or three decades. What started as an enquiry into the childhood roots of resilience has grown into a broad, dynamic and exciting field of study. Resilience theory currently addresses individuals (both children and adults), families, communities, workplaces and policies. Marot and Dunn (2010:2) assert that building organisational capacity and promoting resilience are critical to sustaining organisational effectiveness over the long term. Hucks (2011:1) concurs, taking this further in stating that organisations are finding the need to pull together often, including at times when they are very busy, when change is occurring or when a tragedy or natural disaster strikes.

Hucks (2011:2) asserts that businesses today face continual change and instability, which demand organisational resilience. Resilience is an organisation's capability to respond rapidly to unforeseen change and disruption and determines its ability to bounce back and perform to the expectations of stakeholders. The ability of an organisation to thrive is entirely dependent upon the health, well-being and resilience of management and staff. The emotional strength of everyone is critical for improving communication and creativity. We argue that building resilience in the workplace can lower staff turnover, reduce absenteeism and result in fewer or less severe workplace injuries.

\subsection{Types of resilience}

Patel (2010:3) suggests that there are three main types of resilience.

\subsubsection{Type 1: Resilience in reacting to stressful situations}

The first type of resilience is the 'classic' form, which is the resilience or strength needed to cope with being made redundant, going through bereavement or a divorce at one extreme, to the resilience needed for poor exam results or poor performance reviews or negative/poor performance feedback. In the context of this article, one of the authors needed this type of resilience to survive in a demanding top management office. This type of resilience entails the toughness and humility needed to respond constructively to difficult situations. The key mental challenge is the ability to see beyond today's difficulties and know that tomorrow or the next day or at some point in the future, the situation will change (Cherry 2013:1). Strange as it may seem, this type of resilience is probably easier to deal with, firstly, because the situation is usually in reaction to something or an event of some kind, and secondly, because the situation is usually short term in nature and it is often possible to see some light at the end of the tunnel, even if it is not very close (Patel 2010: 3).

\subsubsection{Type 2: Resilience in creating stressful situations}

The second type of resilience is required to drive change or the determination required to tackle difficult management situations (Cherry 2013:1). These are often the types of situations, such as redundancy, that result in people needing type 1 resilience. However, what both type 1 and type 2 resilience have in common is that they are often a single episode with a beginning, middle and end. Type 2 resilience is a skill which people in challenging situations require far more than type 1, and this is because this type of resilience is about being proactive rather than reactive (Patel 2010:3).

In essence, it is about the leader having a choice about how or whether to make somebody redundant, restructure the department, change working practices, tackle poor performance and so on. So the resilience is needed not just to be proactive but also to deal with the aftermath and fall-out from it. It could be argued that life is rarely as simple as this delineation between type 1 and type 2 resilience. Cuts in expenditure may mean that a leader does not have any choice about restructuring or making people redundant. While it is true that life is rarely clear-cut, I would still argue that type 2 resilience is what leaders need, while type 1 resilience is what followers (for want of a better term) need (Patel 2010:3). 


\subsubsection{Type 3: Resilience in chronic stressful situations}

The third type of resilience is the ability to deal with more or less continuous stressful management challenges. In effect these may be repeated episodes of type 2 resilience strung out over a period of time. It is the kind of resilience typically needed by a CEO or senior director of an organisation, particularly if managing a significant change or if for example, the organisation is affected by the recession or funding cuts. With this kind of resilience it is vital that an individual has a response or set of responses (of the kind set out in section 3) that is stable, not over weeks or months, but in some cases, years (Patel 2010: 3). In this regard, the type of resilience that one of the authors possesses is a combination of 1 and 2, which is about resilience in reacting to stressful situations, because she is working under stress, taking responsibility for her job, her family and school-going children, her peers and her postgraduate studies, as well as the ability to overcome these daunting challenges.

Cherry (2013:1) suggests that resilience is the ability to master oneself by being self-aware, knowing what one stands for and constantly examining the synergy between what one says, feels and does. She goes on to say that it is the ability to maintain peak physical and emotional health and well-being, to endure and sustain periods of high pressure and still take the right decisions, not necessarily the easiest decisions. Patel (2010:15) posits that resilience is about learning from mistakes and improving performance on future occasions and the ability to reduce stress and improve effectiveness by humane, empathetic and networked leadership. It is also about creating a lifestyle that reduces and balances work and domestic pressure, as well as the use of humour and the ability to laugh at oneself.

Marcondes (2011:1) believes that resilient people possess paradoxical personality traits because they approach negative emotions rationally from a problem-focused perspective rather than overreacting, and at the same time, are able to focus on positive emotions rather than stress. They are competent at building strong support networks, and at the same time, possess defined inner psychological spaces. They are realistic about the limitations and challenges being faced, and at the same time, know that they can control or influence what they do to ensure that things work well. They are adaptable and flexible, and at the same time, have very deeply rooted values that allow them to be intensely involved in activities related to their commitment or to find meaning in them. They actively engage in finding solutions to challenges affecting self in intense goal-driven and high-energy ways, and at the same time, can express their feelings in healthy ways.

\section{Literature Review}

Cockram and Van Den Heuvel (2012:3) suggest that resilience is an abstract term that is used substantially across a range of disciplines, such as psychology, sociology, economics, ecology, engineering and network theory, to name but a few. What constitutes resilience is a topic of considerable debate, and meanings differ depending on the nature of the discipline or context in which they are being used. In its most general human context, resilience is defined as 'the ability to recover from or adjust easily to misfortune or change'. Definitions stemming from a systems thinking approach expand on this and include the ability to anticipate, respond and adapt to, and/or rapidly recover from a disruptive event. Secondly, tensions remain across the various disciplines that define resilience, where some focus entirely on an entity's ability to absorb and adapt to impact, and others include the ability to anticipate and mitigate damage. However, in its most generally accepted form, the term resilience refers to the way in which any entity or system achieves an end state of 'keeping going'.

Resilience is defined by Mowbray (2010:1) as the personal capacity to cope with adverse events and return to normal life, 'normal' being idiosyncratic and perceived differently by everyone. He goes on to suggest that it is a psychological feature that contributes towards the prevention of the damaging effects of psychological distress, and that resilient people are able to cope better with adverse events than people with little resilience. Research by Hucks (2011:1) indicates that resilience is the ability to bounce back after a stressful experience, to overcome adversity and even thrive under challenging conditions. Patel (2010:3), however, explains that resilience is not just about how an individual responds to difficult situations, but also about the situations that they choose to make or the choices that they make. With this in mind, a number of people made clear that picking the right organisation to work for, and having the right manager is a key part of reducing the stress of situations. Hoffman (2008:1) concurs, stating that resilience is the ability to persist in the face of adversity and 'bounce back' from setbacks. It comes from a combination of positive attributes we develop through our upbringing, education, social and cultural connections, and other life experiences. These 'resiliency assets' help one to cope with disappointments and stress, overcome obstacles, recover from or adjust to change or misfortune, and deal with the normal stresses and challenges of life. In order to understand resilience, it may help to think of the 
challenges you have faced in life and reflect on how you responded to situations such as a serious illness or injury, divorce or separation, the loss of a job, major changes at work, or even positive changes such as the birth of a new baby or a promotion at work. He further argues that resilience helps us deal with these kinds of challenges and is also an important factor in mental health and in job and career success (Hoffman 2008:1).

In general, the quality of resilience explains how some people seem to be particularly good at dealing with the ups and downs of life and work. There could be many reasons, but people who are good at coping with challenges and setbacks usually have one thing in common: resilience (Patel 2010:3). However, Lewis, Donaldson-Feilder and Pangallo (2011:3) describe resilience in two ways, as explained in the following sections.

\subsection{Resilience at the individual level}

Resilience has a compelling history in psychology and psychiatry. It began with developmental studies of children who were functioning well despite less than healthy family backgrounds. Subsequently, a vast amount of research in the health domain emerged, focusing on the effects of resilience for coping with traumatic situations. This research was broadened to encompass external factors (social/structural) that promote resilience. The finding that certain factors 'buffer' individuals from stressors also fuelled research that has developed related concepts such as hardiness, sustainability, self-efficacy, personal causation, learned resourcefulness, sense of coherence, locus of control, potency and stamina (Garmezy 1993; Glantz \& Sloboda 1999; Luthar \& Cicchetti 2000; Luthar et al. 2000; Ryff et al. 1998).

They add that a consistent theme among the definitions of resilience is a sense of recovery and rebounding despite adversity or change. Most conceptualisations are consistent in identifying resilience as a dynamic process that involves a personal negotiation through life that fluctuates across time, life stage and context. The diversity and complexity of definitions, concepts and approaches used by researchers in the field of resilience renders the task of identifying a precise definition of resilience very difficult.

However, Windle (1999) captures the essence of resilience succinctly and describes it as 'the successful adaptation to life tasks in the face of social disadvantage or highly adverse conditions'. This basic conceptualisation of resilience as adaptation despite adversity is broadly evident; however, resilience is contextual in many ways. Isolated adverse experiences have a significance for resilience that is different from similar experiences occurring alongside other adverse events. Therefore, resilience is best understood as multidimensional and variable across time and circumstance.

\subsection{Resilience at the organisational level}

According to Erica Seville and colleagues (2008), cited by Lewis et al. (2011:4), each organisation has its own 'perfect storm': a combination of events or circumstances that has the potential to bring adversity to any organisation. To overcome this, it is important to define what resilience means for an organisation (independent of the cause of crisis) and to identify the circumstances which pose the greatest threat to survival. Further, it is important to acknowledge that organisations may become more susceptible to adverse events if they have faced many crises, as their resources are stretched and defenses weakened by earlier events.

It is suggested that the greater the diversity of resilience strategies available to an organisation, the greater the ability to respond to challenges. More strategies have the effect of providing a bigger buffer to survive larger crises, or the cumulative effect of more frequent crises. Risk management provides a good framework for organisations to be more proactive in thinking about and managing the unexpected. However, risk management is faced by ontological uncertainties such as 'We don't know what we don't know'. In sum, resilience is conceptualised and defined in exactly the same way for organisations as it is for individuals; however, the key differentiator is the area of focus.

\section{How to Improve Resilience in a Workplace}

Marot and Dunn (2010:3) aver that one of the major concerns for organisations today is developing an agile response to change that allows not only for survival but also for growth. Organisational resilience is the ability to withstand stresses. Organisational resilience is demonstrated by the way change is transmitted throughout the organisation. In effect, resilience is a fundamental quality that is found in individuals, teams and the organisation as a whole. It is central to building positive responses to unexpected events.

They go on to state that the effects of poor organisational resilience are often easily identified and quantified. They are revealed by adverse events, mishaps and how the organisation, team or individuals react to such events. The 
positive face of resilience is somewhat hidden and can be defined by the organisation's intrinsic resilience to operational, internal and external hazards and other pressures. Some organisations are robust in dealing with these pressures; others are not. There is emerging evidence that a positive workplace climate promotes and supports resilience across the organisation. It provides a critical foundation for individuals, teams and the organisation to work effectively through times of change, high pressure and stress.

According to Hoffman (2008:1), the following are the resiliency assets and they have been grouped into five categories to better understand how they work.

- Relationships: the people who give us social and emotional support and practical help.

- Emotional intelligence: the ability to understand and work with our own feelings and those of others.

- Competence: the knowledge and skills that enable us to solve problems and get things done.

- Optimism: the realistic, experience-based positive attitude and thinking pattern that helps us deal with challenges and disappointments with a sense of hope.

- Coping skills: the tools we use to reduce stress and deal with difficult situations.

\section{Relationships}

Relationships with family, friends and colleagues are arguably the most important resiliency assets. Social scientists refer to the social networks and connections that make our lives better as 'social capital'. Research shows that people with lots of social capital are more successful, productive and happy. Spending time with our favourite people and sharing our feelings and experiences helps us to meet challenges in a healthier way and also helps us to approach every day with a positive attitude. In the workplace, positive relationships with supervisors and co-workers make our jobs easier. They also increase our ability to plan, meet goals and deal with challenges. If you are in a leadership position at work, you should know that effective leadership is the most important factor in any company's resilience. Building and maintaining positive relationships with employees, supervisors, co-workers and clients is a key aspect of everyone's job (Hoffman 2008:2).

\section{Emotional Intelligence}

Emotional intelligence is the ability to understand and manage emotions in ourselves and others. It is a crucial life skill that also helps us deal with certain demands in our work lives. The skills associated with emotional intelligence include skills of understanding and relating to other people's feelings; non-verbal communication skills; understanding how our emotions affect others; the ability to use positive emotions to motivate ourselves and inspire others; as well as the ability to manage and control our own feelings when it is important to do so. No one can control all feelings perfectly, but we all need some emotional control. When people are frequently overwhelmed by emotion, it affects their judgment and ability to make decisions. They also find it more difficult to get along with others and recover when they are upset. Emotional skills help us communicate our positive ideas. They also help us express concerns or negative feedback in a way that improves communication and understanding, rather than upsetting people. That is very important in the workplace (Hoffman 2008:4).

\section{Competence}

Sometimes we feel that we can make things happen in our lives. At other times, it seems that things happen to us and are beyond our control. Most people's lives are a mix of the two. However, resilient people feel a greater sense of control in their lives because they have a good understanding of their own competence, their knowledge and skills, their ability to set realistic goals and to make plans to accomplish those goals. Competent people are also curious about how the world works and they use that curiosity to help them learn and improve their skills. Workplace competence helps us feel comfortable in our jobs and equips us to deal with workplace demands. It comes from a combination of our general education and abilities, and the feeling that we have the specific knowledge and skills for the job we are asked to do (Hoffman 2008:5).

\section{Optimism}

According to Hoffman (2008:5), optimistic people are happier and more productive than pessimists. They tend to see 
adversity as temporary and look on obstacles as opportunities. But optimism is not simply the blind belief that things will turn out well. Healthy optimism is authentic. It is based on knowledge, experience, a realistic understanding of our own capabilities, and the ability to assess situations. In the workplace, optimism is especially important when we experience the challenges, and even failures, that are a normal part of work experience. Hoffman states that optimistic people are less likely to develop what he calls 'learned helplessness', a state of mind where people have learned to see themselves as having no ability to control a situation. Learned helplessness increases the risk of depression and reduces people's ability to think and act productively. Seligman's work has also shown that people become more optimistic by learning how to think optimistically, that is, to challenge their negative thinking patterns, especially those involving self-blame.

\section{Coping Skills}

Coping skills are the strategies we use to reduce stress and get through the difficult situations that cannot be avoided. These skills are essential in the workplace because, in spite of our best planning and efforts, everyone experiences stressful situations and setbacks. Some methods of coping, such as heavy drinking, drug use, or bad-mouthing people can be harmful or destructive. Positive coping strategies include taking action to deal with the source of stress itself. Indeed, in our work situation, we have in countless instances dealt with and managed stressful situations. Within the institution there is a wellness programme for emotional support or sympathy from others. Although it is preferable to avoid stressful situations and people when possible, we are unable to do so in our work situation. Hoffman's (2008:1) advice is helpful when he says one has to clear one's mind through deep breathing, meditation, visualisation or other relaxation techniques that one finds helpful.

Mowbray (2010:4) suggests eight features that can build and sustain resilience.

1. Self-efficacy: This involves a high level of self-confidence and a self-belief that one can meet any challenge. Self-Efficacy includes the understanding that, while the world is challenging, one has the ability to succeed despite these challenges.

2. Personal vision: Resilient people know what they believe in and have a clear idea of what they want to accomplish or create in their lives. A personal vision, however blurred this may be, can be used as a guide through life's challenges, and provides them with hope for the future.

3. Flexible and adaptable: Being adaptable and flexible enables people to respond flexibly to unknown challenges by seeking out ways of overcoming events, and being able to adapt to the new reality. This reduces the impact of rigidity in the face of a constantly changing environment.

4. Organised: Creating a structured approach to tasks that need completing adds to the individual's ability to maintain personal control in the face of a seemingly chaotic existence or uncontrollable external events.

5. Problem-solving: The ability to resolve problems enables people to find causes for and solutions to adverse events that impinge on daily life. Those who train themselves to enjoy problem solving will enjoy the challenge that adverse events present.

6. Interpersonal interaction: A key dimension of resilience is an individual's ability to understand and empathise with others. Resilient people demonstrate the competencies of emotional intelligence: a high level of self- and social awareness and the ability to use this awareness to effectively manage themselves and their relationships with others.

7. Social connections: This dimension involves the quality of personal and professional relationships. Resilient people have a strong relationship with selected friends with whom they share ideas, problems, solutions, frustrations, hopes and so forth.

8. Active: Resilient people actively engage in change. Faced with adverse events, resilient people will be assertive in stating their contribution to the changing situation and will maintain personal control through their assertiveness and maintenance of self-efficacy.

\section{The Importance of Resilience in the Workplace}

Hucks (2011:1) points out that resilience is vital as it is what makes people and organisations great. Often the most important business lessons learned will be in response to a challenge faced and overcome. In setting business goals and objectives, the number one priority should be to build resilience, because this skill alone will foster continual development and the ability to adapt. Resilient organisations and people enjoy many advantages, higher levels of engagement, better health, improved morale and less stress. For a business, higher engagement alone translates to increased profitability, 
productivity and customer loyalty. Absenteeism is also lower, as is staff turnover, and innovation increases. According to Hucks (2011:1), a resilient organisation can be characterised by the principles under which it operates, including flexibility to deal with external pressures; inspiring leadership at all management levels; an empowered workforce where trust and accountability are foremost; recruiting resilient people; strong and effective organisational communication; and streamlined systems to ensure high standards. Having discussed the construct of resilience, we believe that it involves a continuous process of learning how to adapt to changing work environments. Although it may be difficult to adjust easily to changing conditions, one has to persist because it is never easy for any of us

\section{Recommendations}

We recommend that, in an attempt to address the problem in this office, the following should be carried out:

- The position should be advertised internally, and a succession plan or promotion policy be put in place. There are a number of administrators/secretaries at different levels in the University (Assistant Administrator, Administrators, Senior Administrator and Executive Secretaries), and when filling this position, Senior Administrators should be given the opportunity to apply and be given the chance for promotion.

- The lower position should be advertised to allow the people in lower positions to apply and the lowest should be advertised externally, applying the 'Growing your own Timber' philosophy.

- The support staff of the Executive Director and the Director should relieve me of their workload or a third person should be appointed as an Assistant/receptionist to run minor errands of the office.

If this can be done, it will create an environment conducive to productivity in the office.

\section{Conclusion}

In every relationship, either at the workplace or between two people or families, everybody needs to be resilient - every parent, every employee, every partner, every student and every new graduate. The degree to which stress and resilience affect people varies from individual to individual. However, understanding how to cope better in the face of challenges and pressure is something all people need at different times in their lives. It is useful to remember that pressure can also be positive. As pressure rises, an organisation can become more motivated and perform better. We all know resilient people. They appear to be able to deal with all of life's ups and downs in a positive way. Even significant set-backs do not send the resilient person off track. There is a confident, positive and optimistic side to resilient people and they appear to have enough energy to work hard and stay motivated and over a sustained period of time. When teams are under pressure it is all the more reason to have resilience in the workplace. Resilient teams are made up of resilient people.

Therefore, the need to focus on building a positive climate in organisations has been propelled by demands of increasingly turbulent conditions and the need for organisations to find stability in these conditions. The ability to identify organisational factors that support positive climates has become more critical than ever before. Time and time again, one of the most influential factors in workplace climate has been found to be leadership practices across the organisation. To effectively build the capacity of organisations, there is strong evidence to show that one should begin by understanding the concept of workplace climate and be able to identify the key components or characteristics of a successful workplace climate.

\section{References}

Cockram, D. \& Van den Heuvel, C. 2012. Organizational resilience. United Kingdom: Business Continuity Institute.

Du Plessis van Breda, A. 2001. Resilience theory: A literature review. South African Military Health Service, Military Psychological Institute, Social Work Research \& Development. Pretoria, South Africa.

Hoffman, J. 2008. Bouncing back: How workplace resiliency can work for you. Partner in Mental Health Leadership. The Psychology Foundation in Canada.

Hucks, A. 2011. Resilience in the workplace. Julie Warburtton Resiliency Specialist. Kardinya, Australia.

Lewis, R. Donaldson-Feilder, E \& Pangallo, A. 2011.Developing resilience. Chartered Institute of Personnel and Development. London.

Patel, B. 2010. The importance of resilience in Leadership. Clore Social Leadership Programme.

Marcondes, P. 2011. Bridging the resilience gap. Sim University. Institute of Management. Singapore.

Marot, M \& Dunn, P. 2010. Building Organisational Capacity and Promoting Resilience - The Importance of Leadership. Volume 2, Issue 1. Noetic Solutions Pty Limited. Australia. 
Mowbray, D. 2010. The eight steps to resilience at work. [Online] Available: http://webcommunities.hse.gov.uk/gf2.ti/f/450/318213/pdf//The\%20eight\%20steps\%20to\%20resilience\%20at\%20work.pdf Accessed: (October 23,2013) 